\title{
TERENGGANU DIALECT UTILIZATION AND RETENTION INSPECT OF MALAY DIALECTS SPOKEN BY BESUT LOCAL COMMUNITIES
}

\author{
Rosdi Zakaria ${ }^{1}$, Noor Rohana Mansor ${ }^{1 *}$, Sharipah Nur Mursalina Syed Azmy리 Mazlina Ahmad ${ }^{1}$, Siti \\ Rahimah Mustaffa 2 \\ ${ }^{1}$ Centre for Fundamental and Liberal Education, Universiti Malaysia Terengganu, 21300 Kuala Nerus, \\ Terengganu, Malaysia \\ 2Universiti Putra Malaysia \\ *noor_rohana@umt.edu.my
}

\begin{abstract}
This study aims to evaluate the use and retention of Terengganu dialects of the state, especially the Malay dialect spoken by the local people of Besut. The goal is to obtain systematic empirical evidence and vocabulary retention ability, especially the local dialect of Terengganu state which is a conservation effort of Malay language treasures. This study intersects qualitative methodology in data analysis inductively and descriptively. Methods of interviews and interviews were recorded and transcribed conversations from informants spoken by Terengganu Malay dialect speakers for accuracy of meaning in data interpretation. The findings show that the usage and retention of the dialect of Besut district, Terengganu has undergone significant changes. The vocabulary in the dialect of Besut district, Terengganu has undergone many changes due to changes in the environment, culture and cultural influence of others. This caused the Besut Malay community to be more influenced and accustomed to using the most dominant words heard in daily speech so many old word expressions were no longer used. Therefore, the researcher finds a deeper study that needs to be done regarding the usage and retention of the dialect of Besut district, Terengganu so that the Besut version of Terengganu subdialect is not fading and can be preserved.
\end{abstract}

Keywords: Vocabulary, Transcription, Inductive, Descriptive, Dominant

\section{INTRODUCTION}

Language has played an important role in shaping culture and cultural retention in the life of a society, this reflects that with the occurrence of language changes, the direct cultural life in life, the social communication life experience in that ethnicity can be said to lead to the use and extent of the process that retention can run smoothly (Asmah, 1982). Accordingly, it is the responsibility of the community in any ethnic group to take care of and respect the dignity of the language in which they speak so that it will be kept and maintained in (Bibi \& Abang, 1993).

Speaking of language dialects of some previous studies which reveal matters concerning the development of Giles et al. (1997), Appel and Muysken (1987) show that the effects of economic change, language shift, led to changes in the dynamics of the use and retention of language (Coluzzi, 2010). This demonstrates the soundness and strength of the dialect of the language itself unlike the former. This indicates that the dialect of the language will change with the moderator and the active driving factor is within the dialect and dialect of the dialect.

Specifically, the use and retention of the language it can be said as a linguistic macro-shaped study which is done in order to see the signs of change and the dimension of the use of the language to the extent of the sustainability and development of the culture of a dialect's (Coupland \& Howard, 1998). In this study, 
researchers will observe issues regarding domains that are born through language-promoting practices that promote the use and retention of the language.

\section{Problem Statement}

In direct and indirect observations conducted by the researchers found that the people in the Besut district did not prioritize and were sensitive to the importance of using local dialects. This can be proven through the experience of researchers looking at the use of dialect language which is no longer so popular in the life of the community in the enclave. This is due to the fact that there is a great lawsuit from the reflection that is derived from the varying verbal frequency of the community. Furthermore, the need for life from the economic network increases the leverage of language influence and the change of language that prevents language self-esteem is no longer seen in daily life.

The impact of globalization and the momentum of modernization was seen to have had a profound and dramatic impact changing the compass of the dialect of the dialect that led to changes to the use and retention (Edwards, 1985). This should be taken seriously by the public and the researchers in order to revive the knowledge of the language. This is in fact not supposed to be the case because it will undermine the credibility of the language that has been supported not only as an intermediary but it also serves as an intermediate essential knowledge which is the communication that creates informal learning among the speakers of the dialect, so that their knowledge developed and continues to be inherited in (Crystal, 2000).

Based on the justification of the research problem as it has been made by the researchers trying to develop a study that will open the eyes and the minds of the general public regarding the importance of the use and retention of language so that it will someday be used as a guide that will trigger the change (Adler, 1971; Fasold, 1984). Indeed, this must be done because the disappearance of the linguistic influence actually occurs silently unknowingly and only sensible is aware of and understands this and has a sense of responsibility to care for, distribute it and use it in everyday speech (Fakuade et al., 2003; Ephorus Huria Kristen Batak Protestant, 2010).

In relation to the study of language, it is found that the lack of research done in relation to the language dialect is whether it is implemented to see development, change, language transition, semantics, semiotic, sociolinguistics (Edwards, 1985; Simanjuntak, 1996). It is the responsibility of a researcher to study and deepen the knowledge deeper in producing more corpus of knowledge that not only gives knowledge to the ethnics itself but also to other ethnicities (Hofman \& Fisherman, 1972).

\section{Purpose of the Study}

Basically this study aims to assess how the use and retention of the dialect of the state of Terengganu, especially the Malay dialect spoken by the local people of Besut. This study is aimed at obtaining empirical evidence through systematic research and empowerment for the preservation of vocabulary is an effort to preserve the Malay language treasures, especially the local dialect of the state of Terengganu.

In this study, language retention refers to the study to know and understand and describe by looking at two things that happen in society, that is, decomposing the current level of language transition, and the second is looking at or analyzing the activities carried out for the preservation of a language when clashing with other dominant languages (Fakuade et al., 2003; Nor, 1994).

\section{Research Objective}

In order to achieve the goal in this study it is done by answering the objectives of the study as outlined below.

i) Identify patterns of dialect language use in Terengganu.

ii) Analyze factors that promote language change.

iii) Systematically exploring the use and retention of languages in the Terengganu territories. 


\section{Scope of Research}

The field of linguistics is a broad study, therefore, the researchers set the scope of a smaller study to study and develop this study in greater depth in order to emerge an invisible corpus of knowledge and never think of what is being considered as an academic study. In this study, the focus of the research provided by the researcher is in dimensions affecting the use and retention of Terengganu dialects, especially the Besut dialect that highlighted the phrase noun, verb and noun.

The emphasis of these three aspects of the language actually presents a great frequency of knowledge to language researchers as well as societies that provide a systematic overview to see the retention and use of language. In addition, researchers and readers will be able to see the direct and indirect aspects of language development in the area of Terengganu.

\section{Limitations of the Study}

In conducting the study, the researchers set the limitations of the research used by researchers in the effort to carry out this study. The purpose of setting the boundaries of the study is to facilitate a more thorough, focused and systematic study. Indeed, the limitation of the study boundaries is very important in the pursuit of the findings of a study that really has a high impact on the rise in the production of earlytreasure treasure.

The limitation of this study is only carried out in the state of Terengganu only and is concentrated in the Besut district only. Justification of Besut district election is because this area is a place where there are many speakers of Besut dialect, active in Terengganu. In addition, the Besut community received a powerful migration and assimilation of language and culture from outside cultures. Hence, in this study the society can assess how far the use and retention of the language can operate in the context of cultural and language environments and see how far the cultural fortress they hold is able to defend the sovereignty of the language that they have been fighting for the remnant of their ancestors for years.

\section{LITERATURE REVIEW}

The study of language has actually been carried out by local and foreign masters and different dimensions, however there are still many studies that have yet to be filled with studies related to language dialect. One of the lessons in this discussion is the study of dialect by Siti et al. (2017), highlighting the study of the retention of Kelantan dialect in the district of Besut, Terengganu. The study explains how Kelantan dialect was preserved in Besut. However, the realities of dialect change have taken place in the area.

Language study uses a psychological approach developed by Giles (1977), which deals with the status, demography, population leading to a study that highlights ethnolinguistic knowledge. While in the study conducted by Prujiner et al. (1984), develop this ethnolinguistic knowledge by exploring social, economic, cultural relations that lead to the ethnolinguistic formation of an ethnos. Uniquely in this study is actually successful in helping to show the relevance of life with the use and retention of the language.

In the previous study we can see through a study by Gal (1979), conducting a study to examine the changes of the local dialect language which is triggered by the changing moods of local economic and political changes. This is because it has an enormous impact on language dynamics to be complex and challenging.

This is in contrast to the study conducted by Nor (1994), which highlighted the research conducted in the interior to examine the development and usage of the language whether it is static or has received change. Uniquely in this study is the fact that the self-knowledge of the community is concerned with the pattern of language dialect change.

\section{METHODOLOGY}


Basically, research conducted by researchers is a descriptive study that uses a qualitative approach. It is done to help deepen the phenomenon of the use and retention of the language that the researchers undergo. In order to obtain data and study materials, researchers use the following methodology of study:

i) Field study-So sure in this study researchers use field research in order to obtain the data that will be used to analyze the study.

ii) Library study-The library study is also a very important resource in conducting this study, in order to obtain the data and materials required in order to obtain the study data.

iii) Internet-In order to improve the degree of data access, researchers use online surveys in order to obtain research data used to support research conducted by researchers.

Unique in this study researchers use a questionnaire that is launched through Google Form based on the focus group discussion concept that this method is a method that is rarely used by any previous researcher. The method of this study is a systematic and effective study as an effective data collection strategy.

The justification for the use of this method is to identify a number of experienced societies in using dialect, so that they respond in this study. Thus, this will facilitate the researcher to compile, store and analyze the subsequent research data to form a quality study result.

\section{RESULTS AND DISCUSSION}

An interview with a group of "Focus Group Discussion" interviews and individual interviews found that some words or vocabularies were not used by Besut dialect speakers. The questionnaire through "Google Form" was also conducted by the researchers to ensure the strength of the issue on the loss of Malay vocal vocabulary of Besut. The use of "Google Form" is addressed to the respondents, speakers of the Besut dialect include age categories among adult speakers.

\begin{tabular}{|c|c|c|c|c|}
\hline$\underline{\mathbf{1}}$ & $\underline{\mathbf{2}}$ & $\underline{\mathbf{3}}$ & $\underline{\mathbf{4}}$ & $\underline{\mathbf{5}}$ \\
\hline$\circ$ & $\circ$ & $\circ$ & $\circ$ & $\circ$ \\
\hline Don't Agree & & & & Strongly Agree \\
\hline
\end{tabular}

\section{0}

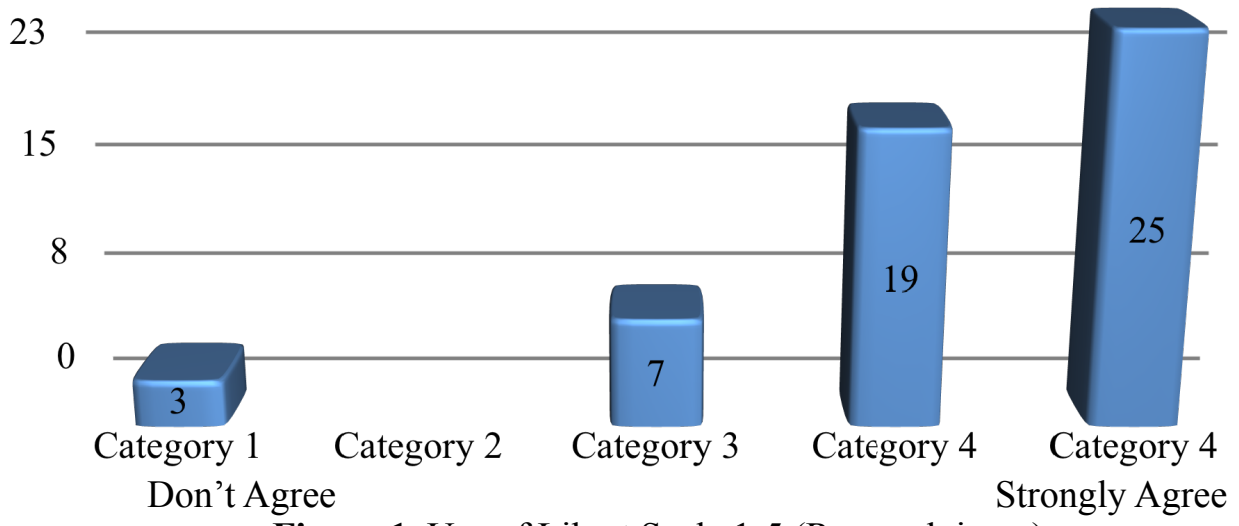

Figure 1. Use of Likert Scale 1-5 (Research issue)

Questions: Do you agree that there has been a change of Malay dialect / word dialect among speakers of the Besut dialect? 
A total of 63 respondents were given a questionnaire through "Google Form" to get an early confirmation of the issues to be undertaken. A total of 54 respondents answered the questionnaire from 63 people.

Based on the findings of this study, it can be analyzed that this study shows the use and retention of language dialect as a whole at a less satisfactory level. This proves and thus provides answers regarding the use and retention of the dialect of the Besut district of Terengganu, which is now widely accepted as a drastic change.

This can be proved by the fact below, indicating the percentage of unused language usage today, but is still known and documented through a systematic study conducted by researchers.

\section{Unrelated Vocabulary Findings \\ Name Phrase}

\begin{tabular}{|c|c|}
\hline Besut Dialect & Definition in Formal Malay (Review the Meaning of the Word) \\
\hline kkati pinei [k:a.ti pi.nêi ] & $\triangleright$ A kind of tool for cutting nutmegs (areca nut) \\
\hline anak curang [a.na? c:u.ra.ng] & $\triangleright$ A kind of a large pan \\
\hline ggaji alang [ g:a.ji a.la.ng] & $\begin{array}{l}>\text { saw saws (a type of tool with a serrated or indented edge for cutting } \\
\text { wood) }\end{array}$ \\
\hline lesung indik [ lê.su.ng in.de? ] & $\triangleright$ A kind of tool used to separate rice skin into rice using leg strength \\
\hline sadat kuek [ sa.dat. ku.e? ] & $\begin{array}{l}>\text { Sadat (a kind of tool for cutting grass using one hand shape like } \\
\text { crescent) }\end{array}$ \\
\hline
\end{tabular}

In the above findings indicate that among the nouns that are no longer used today but have been used actively in ancient times. In fact this is only part of the fact that there are still many noun phrases that have not yet been found and documented and studied what it uses as a word that comes in dialect.

\section{Noun}

\begin{tabular}{|c|c|}
\hline Besut Dialect & Definition in Formal Malay (Review the Meaning of the Word) \\
\hline molo $[$ mo.lo $]$ & $\triangleright$ A tool for storing stuff like a jar \\
\hline rajut [ ra.jut ] & $\triangleright$ A kind of yarn or tangle that is made to store something \\
\hline lonjok [ lon.ja? ] & $\triangleright$ A kind of tool used to store rice food, side dishes and others arranged in layers \\
\hline jebo [je.bo $]$ & $\triangleright$ Some time ago the bottle was called jebo \\
\hline
\end{tabular}

The material presented shows the name that is not used today, it has the specific meaning used by the community in an effort to respond to something about everyday life. 


\section{Verb Phrase}

\begin{tabular}{|c|c|}
\hline Besut Dialect & Definition in Formal Malay (Review the Meaning of the Word) \\
\hline erong kain [ê.ro.ng Pa.in] & $\triangleright$ Cut the cloth using tools like scissors \\
\hline gatih teksi [g:a.têh tع?.si ] & $\triangleright$ The act of attracting trishaw (teksi is also meant as trishaw) \\
\hline pecah peda [ pe.c:oh pe.da ] & $\triangleright$ Actions for bowel movement \\
\hline karih nasi [ ka.reh. na.si?] & $\begin{array}{l}>\text { The act of catching rice after dry water before rice cooked } \\
\text { completely }\end{array}$ \\
\hline
\end{tabular}

The description of the above information describes some of the nouns obtained through the study, this is a preliminary description obtained by the researchers to see the use and retention of the dialect of Besut Terengganu dialect.

\section{Noun Phrase}

\begin{tabular}{|c|c|}
\hline Besut Dialect & Definition in Formal Malay (Review the Meaning of the Word) \\
\hline [ pe.ru.] & $\triangleright$ Sow something that is smooth, grain or dusty \\
\hline jerungai [ je.ru.ng.ai ] & $\begin{array}{l}>\text { Taking something somewhat far from the current situation, it is } \\
\text { necessary to push the body forward }\end{array}$ \\
\hline jijik / jirik [ji.ji? / ji.ri? ] & $\triangleright$ The act of stomping something with a foot \\
\hline [ru.?ah] & $\triangleright$ Act like a tree climb or something high \\
\hline $\begin{array}{cc}\text { ceko } & {[\text { c:c.?o }]} \\
\text { murih } & {[\text { mu.reh }]} \\
\text { irik } & {[\text { i:ri? }]}\end{array}$ & $\begin{array}{l}>\text { Get something using five fingers at once in fist or grip } \\
\triangleright \text { Act of anger } \\
>\text { Removing the padi from the stalk using the legs without a tool }\end{array}$ \\
\hline
\end{tabular}

Verbs are among the different types of words in the dialect language which have undergone many changes as a result of changes in the cultural environment, the influence of other people's cultures and so on that cause the community to be more influenced and accustomed to using the common words or the most dominant they hear in daily speech many old word expressions are still unused.

\section{CONCLUSION}

On the whole, based on the findings of the study, researchers found that the use and retention of the dialect of the dialect of Terengganu's territories of the province is undergoing a significant change, therefore, there is a need for further and deeper research in an effort to resolve this problem rather than continue, the impact will be directly and will not be directly felt by future generations to fail to know, appreciate, understand and most importantly appreciate by preserving the use of language dialect as a cultural symbol. The findings of this study are among the small list of the total loss of language dialect. Imagine that in the future from time to time, the Terengganu subdialect version of the Besut is fading and will not be able to see its authenticity. 


\section{REFERENCES}

Adler, M. (1971). Welsh and other dying languages in Europe: A sociolinguistic study. Helmut Buske Verlag.

Appel, R., \& Muysken, P. (2006). Language contact and bilingualism. Amsterdam University Press. Asmah, O. (1982). Language and society in Malaysia. Dewan Bahasa dan Pustaka.

Bibi, A. A. G., \& Abang, A. R. (1993). Pengekalan dan peralihan bahasa Miriek: Satu pemerhatian. Journal Dewan Bahasa, 37, 703-716.

Bourhis, R. Y., Giles, H., \& Rosenthal, D. (1981). Notes on the construction of a subjective vitality questionnaire for ethnolinguistic groups. Journal of Multilingual and Multicultural Development, 2(2), 145-55.

Coluzzi, P. (2010). Endangered languages in Borneo: A survey among the Iban and Murut (Lun Bawang) in Temburong, Brunei. Oceanic Linguistics, 49(1), 119-143.

Coupland, N., \& Howard, G. (1998). The communicative contexts of accommodation. Language and Communication, 8(314), 175-182.

Crystal, D. (2000). Language death. Cambridge University Press.

Edwards, J. (1985). Language, society and identity. Basil Blackwell.

Ephorus Huria Kristen Batak Protestant. (2010). Almanak Huria Kristen Batak Protestan. Percetakan HKBP.

Fakuade, G., Gambo, M., \& Bashir, A. (2003). Language shift from mother tonguetowards fulfulde in Adamawa State, Nigeria: Causes and consequences. Anthropological Linguistics, 45(3), 296-315.

Fasold, R. W. (1984). The sociolinguistics and society. Basil Blackwell.

Ferguson, C. (1964). Diglossia. In Language in Culture and Society. Harper and Row, pp. 429-437.

Gal, S. (1979). Language shift: Social determinants of linguistic change in bilingual Austria. Academic Press.

Gallois, C., Ogay, T., \& Giles, H. (2005). Communication accommodation theory: A look back and a look ahead. In Theorizing About Intercultural Communication. SAGE, pp. 121-148.

Giles, H. (1977). Language, ethnicity and intergroup relation. Academic Press.

Hofman, J. E., \& Fisherman, H. (1972). Language shift and language maintenance in Israel. In Advances in the Sociology of Language. The Hague, pp. 342- 364.

Johnson, P., Giles, H., \& Bourhis, R. Y. (1983). The viability of ethnolinguistic vitality: A reply. Journal of Multilingual and Multicultural Development, 4(4), 255-269.

Milroy, L. (1980). Language and social networks. Basil Blackwell.

Nor, H. O. (1994). Diglosia di kawasan perumahan Ulu Dedap, Seberang Perak. Dewan Bahasa dan Pustaka.

Prujiner, A., Deshaies, D., Hamers, J. F., Blanc, M., Clement, R., \& Landry, R. (1984). Variaton du compertement langagier lorsque deux langues sont en contact. Centre International de Recherche sur le Bilinguisme.

Sand, A. (1999). Linguistic variation in Jamaica: A corpus-based study of radio and newspaper usage. Gunter Narr Verlag.

Simanjuntak, M. (1996). Pupus bahasa pupuslah bangsa, maju bahasa majulah negara. Persatuan Linguistik Malaysia.

Siti, R. M., Raja, M. R. A., Adi, Y. A. A., \& Mohd, S. Y.. (2017). Pelestarian dilaek Kelantan di Besut dan kaitannya dengan pembentukan jati diri. Jurnal Bahasa, 17(1), 145-173.

Submit Date: 05.07. 2018, Acceptance Date: 24.08.2018, DOI NO: 10.7456/1080SSE/118

Research Article - This article was checked by Turnitin

Copyright $(\mathbb{C}$ The Turkish Online Journal of Design, Art and Communication 